\title{
BI as a service: an attempt to understand the leading adoption factors
}

\author{
Marco De Marco ${ }^{1}$ Cecilia Rossignoli $^{2}$ Antonella Ferrari ${ }^{2}$ Lapo Mola $^{2}$ \\ Alessandro Zardini \\ ${ }^{1}$ Catholic University, Dipartimento di Scienze dell'economia e della gestione aziendale, \\ Milan (Italy) \\ ${ }^{2}$ University of Verona, Business and Administration Department, Verona (Italy)
}

\begin{abstract}
The research question of this study attempts to identify which are the leading factors for the adoption of a sourcing Software as a Service model for Business Intelligence applications. The objective is to build a model containing enabling factors for the adoption of BI solutions. We seek to expand on the Benlian et al. model [1] which is based on a theoretical framework including axioms from Transaction Cost Theory, Resource Based View, Theory of Planned Behavior. In order to better understand the phenomenon under investigation, we will use also the Organizational Culture Theory. It is a theoretical research in progress.
\end{abstract}

Keywords: Software as a Service, Business Intelligence adoption, Enabling Factors

\section{Introduction}

According to Zeljko Panian, "Business Intelligence allows organizations to access, analyze and share information and knowledge. This helps them to track, understand, target and manage their business in order to improve enterprise performance" [2,3]. Software as a Service (SaaS) for Business
Intelligence (BI) could be defined as BI functions and applications that are supported by a vendor as a service, accessed over the Internet, without the need to deploy and maintain an onpremises solution. SaaS-based BI enables customers to quickly deploy one or more of the prime components of BI without significant IT involvement. Gartner asserts that by 2011, 25\% of business software will be provided through SaaS.

The research question of this study attempts to identify which are the enabling factors for the adoption of a sourcing SaaS model for Business Intelligence applications.

Is it possible to individualize a decisional course in choosing to adopt a SaaS approach for BI applications?

The SaaS approach can be defined as a demand-driven application sourcing model which provides network-based access for firms to an integrated portfolio of applications spanning the complete virtual value chain of an enterprise [4]. Hence, SaaS solutions are on-demand applications as opposed to on premises applications. This is because the organization purchases only what is needed, when needed, for only the necessary users instead of purchasing the application for in-house installation on site. From another perspective, the SaaS approach can be 
considered a software delivery model in which a vendor hosts, operates and manages a software service for use by its clients on a paid subscription basis. SaaS can be used to support Business Intelligence applications for use over the Internet [5].

Software as a Service in the context of $\mathrm{BI}$ is comprised of two components: BI applications and Platform as a Service (PaaS). The PaaS provides those services which support on demand BI applications. It is formed by three components: BI development services, data integration services and data management services.

The objective of this paper is to propose a model containing enabling factors for the adoption of BI solutions. We seek to expand on the Benlian et al [1] model which is based on a theoretical framework including axioms from Transaction Cost Theory, Resource Based View and Theory of Planned Behavior (fig. 1). We would add the Organizational Culture Theory that can improve the model and provide a more complete explanation.

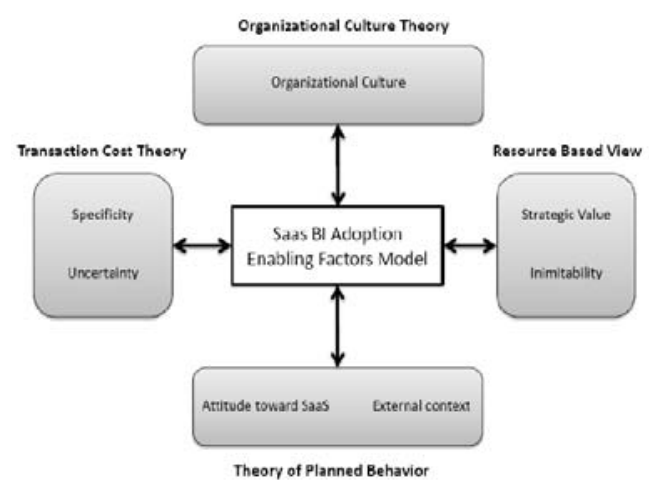

Fig. 1: The theoretical framework.

This is a theoretical research in progress which provides a first step towards a qualitative approach based on case study for the practical evaluation of the new model.

\section{The theoretical background}

Software as a Service is gaining significant attention from the specialized press and Information Systems literature, with varying assessments. Some researchers predict the collapse of SaaS [6] while others expect an increasing rate of adoption [7]. Several articles have referred to TCT to explain IT outsourcing choice and recently other theories have been adopted to explain the outsourcing strategies of various enterprises. For example Kern and Willcocks [8, p. 322] describe IT outsourcing as "a decision taken by an organization to contract-out or sell the organization's IT assets, people and/or activities to a third party supplier, who in exchange provides and manages assets and services for monetary returns over an agreed time period".

In this study we started from a paper by Benlian et al [1] in which the authors attempt to identify the drivers of SaaS adoption.

In a previous paper Benlian and Hess [9] identified "application specificity" as the most significant driver of application adoption based on the SaaS approach. Application specificity is a basic concept in TCT. Referring to this theory "the higher the degree of application specificity, the lower the level of outsourcing" [5] . From this assertion we can derive the following hypothesis.

H1: Application specificity is negatively related to SaaS BI adoption.

Another factor which negatively influences outsourcing strategies is uncertainty $[10,11]$. Several studies conducted by influential scholars 
verified the validity of this relationship $[12,13,14]$.

The concept of uncertainty is closely related to the frequent changes in economic, organizational and technological contexts in which software applications must operate. The previous statements will form the basis of the second hypothesis.

H2: Adoption uncertainty is negatively related to SaaS BI adoption.

Another theory used by scholars to explain outsourcing phenomena is the Resource Based View [15]. According to this theory, a sustained competitive advantage is strictly dependent on an organization's resource base. These resources can be tangible or intangible, but they should be exceptional, inimitable and non substitutable. In the past, Porter and Millar [16] and, more recently, Clemmons and Row [17] underlined the role of information systems in creating sustained competitive advantage. From these assumptions we can argue that organizations will attempt to outsource processes or functions which are not considered as critical from the strategic management point of view. For this reason, according to Benlian et al [1] , it is possible to define the $\mathrm{H} 3$ and $\mathrm{H} 4$ hypotheses.

H3: The application's strategic value is negatively related to SaaS BI adoption

H4: The application's inimitability is negatively related to SaaS BI adoption.

Another theory proposed by Benlian et al. [1] to understand the drivers of SaaS adoption is the Theory of Planned Behavior. The theory of Planned Behavior TPB asserts that individual behavior will be driven by specific intentions which depend on three elements: the individual attitude toward the behavior, the subjective norms surrounding the performance of the behavior, and the individual's perception of the ease with which the behavior can be performed (behavioral control) ([18, 19, 20]. Certainly any management decision, in this case decisions of IS executives, are influenced by external context and by other factors. These factors could be, for example, expected consequences of utilization, affects toward using IT [21]. Adopting the theory of planned behavior for this study, the decision for or against the adoption will depend on individual intention and will be influenced by the attitude towards the behavior and the subjective norms. Starting from the Benlian et al. [1] study and adapting their perspective to $\mathrm{BI}$ applications, it is possible to assert that attitudes toward SaaS BI adoption can be considered as the general evaluative appraisal of an IS executive toward utilization of BI applications in a SaaS environment. From these assumptions we define the following hypothesis.

H5: Application specificity, adoption uncertainty, strategic value and application inimitability are associated in a negative way with attitudes towards SaaS BI adoption.

Another aspect which must be considered as a factor influencing IT outsourcing strategies is external influence. Researchers demonstrate how the option to outsource is due to imitating behavior and not to rational reasoning [22]. This concept can be summarized asserting that external context can play a significant role in IS outsourcing decisions. From this consideration we can derive the following hypothesis.

H6: External context can be positively related to attitudes towards SaaS BI adoption.

The Organizational Culture Theory is defined typically in terms of the way people think, which has a direct 
influence on the ways in which they behave [23]. Schein [24] suggests that the essence of culture lies in the set of "underlying assumptions." Similarly, Deshpande and Webster [25, p.4] define organizational culture as a "set of shared assumptions and understanding about organization functioning". A firm's culture therefore, through its values and operating beliefs, exerts commanding influences on how its employees perceive events [23, 26]. Researchers seem to agree that culture may be an important factor in determining how well an individual fits an organizational context [24].

Hence the organizational culture can improve the possibility of Business Intelligence adoption by fostering a desired culture, in addition to its direct effect on SaaS BI adoption. Organizational culture is crucial for the effectiveness of IT adoption and for the sourcing strategies adopted by an organization [23, 28].

H7: Leadership can proactively foster an organizational culture conducive to SaaS BI adoption.

\section{The theoretical framework}

IS literature proposes several models which analyse the enabling and critical factors of BI applications adoption [29, 30]. We summarized these factors, grouping them in three categories, and linked them with the hypothesis of Benlian Hess and Buxmann [1] which was modified considering the specificity of BI applications. The three categories are: organizational factors, economic factors and technological factors. The final framework which emerged from this link is proposed in figure 2 .

\subsection{Specificity (H1)}

To outsource applications which have a high level of specificity an investment in coordination and integration costs is required. Organizational enabling factors which influence in a negative way the level of specificity can be considered the critical operative processes: if a process is critical the risks deriving from outsourcing are too high. Moreover, other competencies could be essential which are the not available to the provider. The same reasoning could be applied to certain other factors such as optimization of operative processes, optimization of operative risks or optimization of the processes' performance levels. Other factors which influence specificity in a negative way are technological factors which require a high level of user involvement and increased participation of the IT department. These factors are: frequent level of updating, high degree of personalization, security, assistance, user friendliness, integration and adequate technical requirements.

\subsection{Uncertainty (H2)}

From an organizational point of view, uncertainty could be present within operative processes given their critical nature: if BI application supports operative processes which could be considered "core", it would be better to avoid SaaS solutions. Choosing one provider and not another affects the results due to the fact that the right provider must have a deep knowledge of the enterprise's operative processes. Nevertheless there are some factors which could have a positive influence in supporting the adoption of this type of sourcing model. These factors are: management support, user and IT department support, user and IT department acceptance. The greater the presence of these factors, the lower the uncertainty related to this sourcing 
model. Economic factors which could influence uncertainty in a positive way, in the sense that they reduce it by enlarging awareness of potential obtainable benefits are: optimization of hardware, software and personnel costs, economies of scale and the optimization of application performance. Moreover it is necessary to consider contractual forms: if these are well defined they should guarantee certainty about the given services provided, considering also the reputation of the provider.
There are some technological elements which could facilitate the choice of a SaaS application, influencing uncertainty in a positive way. They are basic requirements for technological adequacy, initialization process optimization, adequate functionality and volume scalability, the possibility of application transfer to the company itself and guaranteed business assistance. All these elements will impact the performance of the application.

\begin{tabular}{|c|c|c|c|c|c|c|c|c|}
\hline & & Specificity & Uncertainty & Strategic value & Inimitability & Attitude & External context & $\begin{array}{l}\text { Organizational } \\
\text { Culture }\end{array}$ \\
\hline \multirow{17}{*}{ 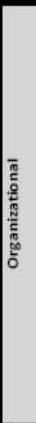 } & Company Strategy & & & & & $(+)$ & $(+)$ & $(+)$ \\
\hline & Company Culture & & & & & $(+)$ & $(+)$ & $(+)$ \\
\hline & Relevance of operative processes & $(-)$ & $(-)$ & $(-)$ & $H$ & & & \\
\hline & IT skill suitability & $(-1)$ & & & $(-1)$ & & & $(+)$ \\
\hline & IT-BUSINESS relationship effectiveness & & & $(+)$ & & & & $1+1$ \\
\hline & IT resources optimization & & & & & & & \\
\hline & Operational processes optimization & $(-)$ & $(-)$ & & & & & \\
\hline & Vendor/Supplier & & $H$ & $(+)$ & & & $(+)$ & \\
\hline & Tinvolvement & $(-)$ & & & & & & \\
\hline & USER involvement & $H$ & & & & & & $(+)$ \\
\hline & IT commitment & & $(+)$ & $(+)$ & & $(+)$ & $(+)$ & $1+1$ \\
\hline & MNGT commitment & & $(+)$ & $(+)$ & & $(+)$ & $1+1$ & \\
\hline & USER commitment & & $(+)$ & $(+)$ & & $(+)$ & $(+)$ & $(+)$ \\
\hline & T-BUSINESS coordination & $(-)$ & & & & & & $\frac{1}{(+)}$ \\
\hline & T-BUSINESS collaboration & $H$ & & & & & & $(+)$ \\
\hline & T acceptance & & $(+)$ & $(+)$ & & & & $1+1$ \\
\hline & USER acceptance & & $(+)$ & $1+1$ & & & & \\
\hline \multirow{7}{*}{ 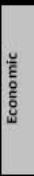 } & Dptimization of HW-SW-INFRASTRUCTURE costs & & $(+)$ & & & & & $(+)$ \\
\hline & Optimization of human resources costs & & $(+)$ & & & & & \\
\hline & Scale economies & & $(+)$ & $(+)$ & & & & \\
\hline & Operational risks optimization & $(-)$ & & & & & & \\
\hline & ROI & & $(+)$ & $(+)$ & & & & \\
\hline & Optimization of Process performance & $(-)$ & $(+)$ & & $H$ & & & \\
\hline & Contract procedures & & $+(+)$ & & & & & \\
\hline \multirow{11}{*}{ 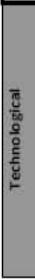 } & Application performance & & $(+)$ & $(+)$ & & & & \\
\hline & \begin{tabular}{|l|} 
Optimization of Inizialization process \\
\end{tabular} & & $(+)$ & & & & & \\
\hline & Scalability of functionality and volumes & & $1+1$ & & & & & \\
\hline & \begin{tabular}{|l|} 
Update \\
\end{tabular} & $(-)$ & $(+)$ & & $H$ & & & \\
\hline & \begin{tabular}{|l|} 
Personalization \\
\end{tabular} & 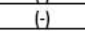 & & & $H$ & & & \\
\hline & \begin{tabular}{|l|} 
Security \\
\end{tabular} & $H$ & & & $H$ & & & \\
\hline & \begin{tabular}{|l|} 
Assistance \\
\end{tabular} & $(-)$ & $(+)$ & & $(-)$ & & & \\
\hline & \begin{tabular}{|l|l|} 
Ease use \\
\end{tabular} & $(-1)$ & & & $H$ & & & $(+)$ \\
\hline & \begin{tabular}{|l|} 
Integration \\
\end{tabular} & $(-1)$ & & & $H$ & & & $(+)$ \\
\hline & House portability & & $(+)$ & & & & & \\
\hline & Suitability of basic technolog gical requirements & $(-)$ & $(+)$ & & $\theta$ & & & \\
\hline
\end{tabular}

Fig. 2: Enabling factors and their links with the hypotheses.

\subsection{Strategic value (H3)}

Strategic value of the application could be influenced in a negative way by the critical nature of certain processes which support the application. In this situation SaaS couldn't be considered a convenient solution. Nevertheless, there are other economic and organizational elements which could enable a SaaS approach if combined with the strategic role of a BI solution, such as an 
effective relationship between the IT department and users, a strong commitment by management and by the IT department and users or a good supplier reputation. Moreover, economies of scale deriving from SaaS adoption.

\subsection{Inimitability (H4)}

The concept of inimitability in BI application context is strictly related to the concept of specificity. For this reason, the defined elements influencing specificity which have negative effects on SaaS adoption are also the same for inimitability. The core operative processes and the high level of competencies are elements which reduce the opportunity for an outsourcing solution. The same reasoning can be made regarding an application which requires a high level of personalization and technical support.

\subsection{Attitude (H5)}

Attitudes towards SaaS adoption could be implicitly considered as embedded within the culture and strategic objectives of an enterprise: it is reasonable to propose that these elements will influence in a positive way the choice of an outsourcing solution. Management, IT department, and user commitment can act as enablers, because they implicitly reflect the enterprise culture which is usually well oriented towards new IT sourcing models.

\subsection{External context (H6)}

External context influences both the reference environment and strategic decisions. Considering this fact, we can propose that all factors which influence SaaS adoption in a positive way will be organizational elements related to strategy and business culture. To these elements must be added the predisposition of management and of the IT department towards BI SaaS solution.

\subsection{Organizational Culture (Leadership, H7)}

The role played by top management should be considered crucial for the adoption of BI SaaS. One can say that SaaS can be viewed as a sourcing strategy that implies a loss of control on own data. Companies that are not familiar with cooperation and collaborative strategies can negatively approach such BI sourcing strategy. Companies that practice outsourcing or global sourcing strategies could be more inclined to deploy a Saas strategy for their BI solutions [31]. Software development behind the solution, since SaaS vendors must accommodate a number of design and development issues when changing their solution from an on-premises, single-instance, packaged software architecture to the new multi-tenant architecture [32].

\section{Conclusions}

This paper seeks to establish a conceptualization of the enabling factors in SaaS Business Intelligence adoption. There is a lack of IS literature in this field of study and for this reason the authors sought to propose the research herein. It is a theoretical research in progress which provides a first step towards a qualitative approach, based on multiple-case study, for the practical evaluation of the proposed model.

The new model will consider all the three categories of factors: organizational, economic and technological and their relationships with the indicated $\mathrm{H} 1-\mathrm{H} 7$ hypotheses. 


\section{References}

[1] Benlian, A., Hess T. and Buxmann, P., "Drivers of SaaS-Adoption-An Empirical Study of Different Application Types", Business \& Information Systems Engineering, 5: pp. 357-368, 2009.

[2] Panian, Z., "Business Intelligence in Support of Business Strategy", Proceeding of the 7th WSEAS International Conference on Mathematics \& Computer in Business Economics, Cavtat (Croatia), 13-15 June, pp. 204-215, 2006.

[3] Weixin, Y., and Lihua H., "Event Driven Business Intelligence - A New Cutting Edge of Business Competition", Science \& Technology Review, pp. 59-61, 2004.

[4] Buxmann, P., Hess T. and Lehmann, S., "Software as a Service", Wirtschaftsinfor matik, 50(6): pp. 500-503, 2008.

[5] Imhoff, C., and White, C., "An Evolutionary Approach to Master Data Management", Business Intelligence Network Research Report, January, 2009.

[6] Jung, J. and Bube, L., "Software as a Service wird kollabieren", Accessed 2009-09-13. http://www.networkcomputing.de/s oftware-as-a-service-wirdkollabieren/, 2008.

[7] Prehl, S., "Software as a Sevice erreicht Europa", Accessed 200806-30.

www.computerwoche.de/knowledge center/it_services/1870304/, 2008.

[8] Kern, T., and Willcocks, L., "Exploring information technology outsourcing relationships: theory and practice", Journal of Strategic Information Systems, 9(2000): pp. 321-350, 2008.
[9] Benlian, A., and Hess, T., "Welche Treiber lassen SaaS auch in Großunternehmen zum Erfolg warden? Eine empirische Analyse der SaaS-Adoption auf basis der Transaktionkostentheorie", Proceedings of the 9th international conference Wirtschaftinformatik, Vol. 1, Vienna, 2009.

[10] Williamson, O.E., "Comparative economic organization: The analysis of discrete structural alternatives", Administrative Science Quarterly 36(2): pp. 269296, 1991.

[11]Blumberg, S., Beimborn, D., and Koenig, W., "Determinants of IT outsourcing relationships: a conceptual model", Proceedings of the 41th Hawaii international conference on system sciences, Waikoloa, 2008.

[12] Nam, K., Rajagopalan, S., Rao, H.R. and Chaudhury, A., "A twolevel investigation of information systems outsourcing", Communications of the ACM 39(7): pp. 37-44, 1996.

[13] Aubert, B., Rivard, S.and Patry, M., "A transaction cost model of IT outsourcing", Information and Management 41(7): pp. 921-932, 2004.

[14] Dibbern, J., "Sourcing of application software services. Empirical evidence of cultural, industry and functional differences". Physica, Heidelberg, 2004.

[15]Barney, J., "Firm resources and sustained competitive advantage", Journal of Management 17(1): pp. 99-120, 1991.

[16] Porter, M.E. and Millar, V.E., "How information gives you competitive advantage", Harvard Business Review, 63(4): pp. 149$160,1980$. 
[17] Clemmons, E.K., Reddi, S.P. and Row, M.C., "The Impact of Information Technology on the Organization of Economic Activity: The 'Move to the Middle' Hypothesis", Journal of Management Information Systems, 10(2): pp. 9-35. 1991.

[18] Ajzen, I., "From intentions to actions: A theory of planned behavior". In J. Kuhl, \& J. Beckmann (Eds.), Springer series in social psychology, p. 11-39. Berlin: Springer, 1985.

[19]Ajzen, I., "The theory of planned behavior", Organizational Behavior and Human Decision Processes, 50(2): pp. 179-211, 1991.

[20]Eagly, A. H., and Chaiken, S., "The psychology of attitudes". Fort Worth: Harcourt Brace Jovanovich College Publishers, 1993.

[21] Goodhued, D.L. and Thompson, R.L., "Task-Technology Fit and Individual Performance", MIS Quarterly, June 1995, 19 (2): pp. 213-236, 1995.

[22] Lacity, M., Hirschheim, R., and Willcocks, L., "Realizing outsourcing expectations: incredible promise, credible outcomes", Journal of Information Systems Management, 11(4), pp. 7-18, 1994.

[23] Ke, W., and Wei, K.K., "Organizational culture and leadership in ERP implementation", Decision Support Systems, 45(2): pp. 208-218, 2008.

[24] Deshpande, R., and Webster, F.E., "Organizational Culture and Marketing-Defining the Research Agenda", Journal of Marketing, 53(1): pp. 3-15, 2007.

[25] Denison, D.R., and Mishra, A.K., "Toward a Theory of Organizational Culture and Effectiveness", Organization Science 6(2): pp. 204-223, 1995.
[26] Schein, E., "Organizational culture and leadership". San Francisco: Jossey-Bass, 1985.

[27] Martinsons, M.G., and Chong, P.K.C., "The influence of human factors and specialist involvement on information systems success", Human Relations, 52(1): p. 123-152, 1999.

[28]Vera, D., and Crossan, M., "Strategic leadership and organizational learning", Academy of Management Review 29(2), pp. 222-240, 2004.

[29] Clark, D.T., Jones, M.C. and Armstrong, C.P., "The dynamic structure of Management Support System: theory development, research focus, and direction", MIS Quarterly, 31(3), pp. 579-615, 2007.

[30]DeLone, W., and McLean, E.R., "The DeLone and McLean Model of Information Systems Success: A Ten-Year Update", Journal of Management Information Systems, 19(4), pp. 9-30, 2003.

[31] Waldman, D., Ramirez, G., House, R.J., and Puranam, P., "Does leadership matter? CEO leadership attributes and profitability under conditions of perceived environmental uncertainty", Academy of Management Journal, 44(1), pp. 134-143, 2001.

[32] Hessler, D., "How to drive down lab operating costs with webdelivered software-as-a-service", Rubber World, 242(4), pp. 18-89. 